\title{
Linear Model of the Jet-type Hydraulic Amplifier Based on Hydraulic Resistance Network
}

\author{
Yuesong Li \\ Department of Mechanical and Electrical Engineering, Henan University of Science and Technology, \\ Luoyang, 471003, China \\ liyaosong707@163.com
}

Keywords: Jet-type hydraulic amplifier; hydraulic resistance network; flow continuity equation; pressure characteristic; flow characteristic.

Abstract. As the core element of jet-type servovalve, the linear model of jet-type hydraulic amplifier (JTHA) is important for analyzing and controlling the jet-type servovalve. Based on the function between flow area and the jet nozzle's displacement, the linear model of JTHA is derived from hydraulic bridge's flow balance equation, then the pressure characteristic equation and flow characteristic equation are given. At last, the effect of the distance of two receivers and the area ratio on pressure and flow rate are given.

\section{Introduction}

The jet-type servovalve has strong anti-pollution capacity, high reliability, long service life and other advantages, it is widely used in flight control system and fuel control system in the aerospace field [1-5]. As the core element of jet-type servovalve, the linear model of jet-type hydraulic amplifier (JTHA) is important for analyzing and controlling the jet-type servovalve. In the dynamic performance analysis and control, the model of JTHA is needed to be linearized. This paper will introduce a linearization method of the JTHA model based on full-bridge hydraulic resistor network, this linear model can be applied to analysis and control of jet-type servovalves.

\section{Operating principle of JTHA}

Fig. 1 shows the operating principle of JTHA, the jet nozzle divides the two receiver holes into four adjustable orifices. $e$ is the distance between left and right receiver holes; $y$ is the displacement of jet nozzle. When the jet nozzle is in the middle position between two receiver holes, due to $A_{1}=A_{2}$, the kinetic energy in receiver holes is equal; when the jet nozzle moves a displacement, the flow area $A_{1} \neq A_{2}$, the kinetic energy received by receiver holes are no longer equal, one increases and the other decreases, therefore the receiver holes have differential pressure driving the spool move.

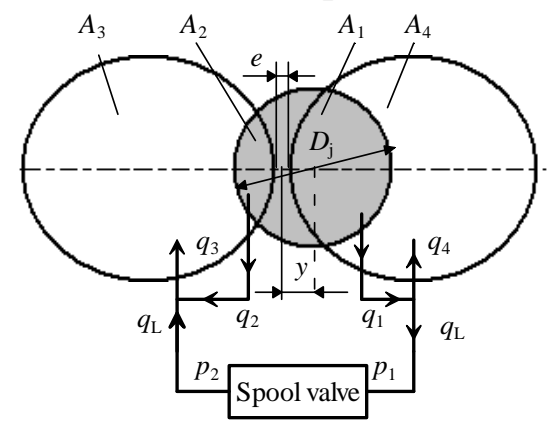

Fig. 1 Operating principle of JTHA

\section{Model of JTHA}

Flow area's model of adjustable orifices. Fig.1 shows the JTHA is the symmetry. If the friendships between flow areas and the displacement are linear, flow areas can be defined as

$$
A_{1}(y)=A_{1}(0)+\beta y
$$




$$
\begin{aligned}
& A_{2}(y)=A_{1}(0)-\beta y \\
& A_{3}(y)=\pi R_{\mathrm{r}}^{2}-A_{1}(0)+\beta y \\
& A_{4}(y)=\pi R_{\mathrm{r}}^{2}-A_{1}(0)-\beta y
\end{aligned}
$$

Where $\beta$ is area gradient near $y=0$.

Fig. 2 shows the flow area when the projection receiver hole and the jet nozzle on the receiving plane are inscribed and circumscribed, respectively.

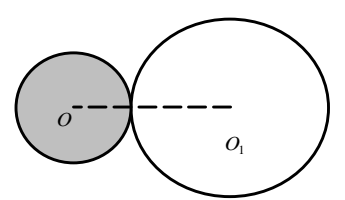

(a) circumscribed

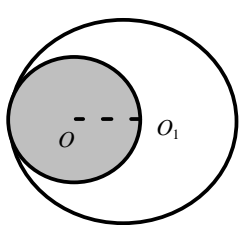

(b) inscribed

Fig. 2 Flow areas under inscribed and circumscribed

As shown in Fig.2(a),when the jet nozzle circumscribes receiver hole, the displacement of the jet nozzle is

$$
y=0.5 e+R_{\mathrm{r}} / \cos \theta_{\mathrm{r}}-\left(R_{\mathrm{r}} / \cos \theta_{\mathrm{r}}+R_{\mathrm{j}}\right)=0.5 e-R_{\mathrm{j}}
$$

The flow area is

$$
\left.A_{1}(y)\right|_{y=0.5 e-R_{\mathrm{j}}}=A_{1}(0)+\beta_{1}\left(0.5 e-R_{\mathrm{j}}\right)=0
$$

Where, $R_{\mathrm{r}}$ is the radius of the receive holes; $R_{\mathrm{j}}$ is the radius of the jet nozzle.

As shown in Fig.2(b), When the jet nozzle inscribes receiver hole, the displacement of the jet nozzle is

$$
y=0.5 e+R_{\mathrm{r}} / \cos \theta_{\mathrm{r}}-\left(R_{\mathrm{r}} / \cos \theta_{\mathrm{r}}-R_{\mathrm{j}}\right)=0.5 e+R_{\mathrm{j}}
$$

The flow area is

$$
\left.A_{1}(y)\right|_{y=R_{\mathrm{j}}+0.5 e}=A_{1}(0)+\beta_{1}\left(R_{\mathrm{j}}+0.5 e\right)=\pi R_{\mathrm{j}}^{2}
$$

Solving Eq. (6) and (8) can be got

$$
A_{1}(0)=\frac{\pi}{2} R_{\mathrm{j}}\left(R_{\mathrm{j}}-0.5 e\right), \beta=\frac{\pi}{2} R_{\mathrm{j}}
$$

Substituting Eq.(9) into (1) (4), the linear model can be written as

$$
\begin{gathered}
A_{1}(y)=\frac{\pi}{2} R_{\mathrm{j}}\left(R_{\mathrm{j}}-0.5 e+y\right) \\
A_{2}(y)=\frac{\pi}{2} R_{\mathrm{j}}\left(R_{\mathrm{j}}-0.5 e-y\right) \\
A_{3}(y)=\pi R_{\mathrm{r}}^{2}+\frac{\pi}{2} R_{\mathrm{j}}\left(0.5 e-R_{\mathrm{j}}+y\right) \\
A_{4}(y)=\pi R_{\mathrm{r}}^{2}+\frac{\pi}{2} R_{\mathrm{j}}\left(0.5 e-R_{\mathrm{j}}-y\right)
\end{gathered}
$$

Pressure-flow model. From the above analysis, the output of JTHA can be equivalent to the full-bridge hydraulic resistor network shown in Fig. 3. 


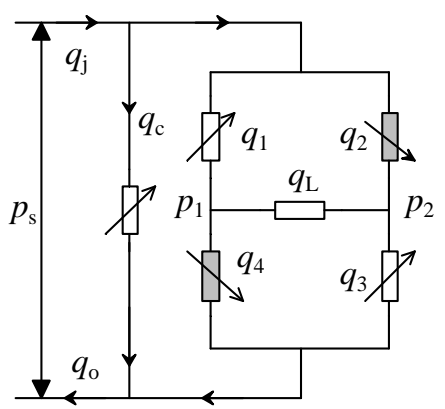

Fig.3 Full-bridge Circuit of JTHA

From Fig. 4 and the flow equation of continuity, the following relations can be derived

$$
\begin{gathered}
q_{\mathrm{L}}=q_{1}-q_{4}=C_{\mathrm{d}} A_{1} \sqrt{\frac{2}{\rho}\left(p_{s}-p_{1}\right)}-C_{\mathrm{d}} A_{4} \sqrt{\frac{2}{\rho} p_{1}} \\
p_{\mathrm{L}}=p_{1}-p_{2} \\
q_{\mathrm{L}}=q_{3}-q_{2}=C_{\mathrm{d}} A_{3} \sqrt{\frac{2}{\rho} p_{2}}-C_{\mathrm{d}} A_{2} \sqrt{\frac{2}{\rho}\left(p_{s}-p_{2}\right)}
\end{gathered}
$$

where, $C_{\mathrm{d}}$ is flow coefficient; $\rho$ is oil density; $p_{\mathrm{s}}$ is oil pressure, $p_{1}$ and $p_{2}$ are the pressure values of left and right receiver holes, respectively.

Pressure characteristics. The pressure characteristics of JTHA are often derived from the load flow of zero, and are expressed by the relation curve between the output pressure and the jet nozzle displacement.

Substituting $q_{\mathrm{L}}=0$ into Eqs.(15) (16), the pressure characteristics can be derived as

$$
p_{\mathrm{L}}(y)=\left(\frac{A_{1}^{2}(y)}{A_{1}^{2}(y)+A_{4}^{2}(y)}-\frac{A_{2}^{2}(y)}{A_{2}^{2}(y)+A_{3}^{2}(y)}\right) p_{s}
$$

Near $y=0$, linear pressure characteristics can be written as

$$
p_{\mathrm{L}}=K_{\mathrm{p} 0} y=\frac{\partial p_{L}}{\partial y} y=\frac{k_{\mathrm{rj}}}{1+\left(2 k_{\mathrm{rj}}-1\right)^{2}} \frac{2 k_{\mathrm{rj}}-1}{\left(k_{\mathrm{rj}}-1\right)^{2}+k_{\mathrm{rj}}^{2}} \frac{4 p_{\mathrm{s}}}{R_{\mathrm{j}}} y
$$

where

$$
k_{\mathrm{rj}}=\frac{A_{\mathrm{r}}}{A_{\mathrm{j}}}=\frac{R_{\mathrm{r}}^{2}}{R_{\mathrm{j}}^{2}}
$$

Flow characteristics. Flow characteristics are generally described by the relation between the load flow and the jet nozzle displacement when the loading pressure is zero. That is to analyze, when $p_{\mathrm{L}}=0$, the relation between the output flow $q_{\mathrm{L}}$ and the displacement $y$.

If $p_{1}=p_{2}$, flow characteristics equation can be derived from equations (15) to (16) as

$$
q_{\mathrm{L}}=\frac{\frac{\sqrt{2}}{2} k_{\mathrm{rj}} \frac{A_{1}-A_{2}}{A_{\mathrm{j}}} q_{\mathrm{j}}}{\sqrt{\left(k_{\mathrm{rj}}-\frac{A_{1}}{A_{\mathrm{j}}}\right)^{2}+\left(k_{\mathrm{rj}}-\frac{A_{2}}{A_{\mathrm{j}}}\right)^{2}+2 \frac{A_{1} \cdot A_{2}}{A_{\mathrm{j}}^{2}}}}=\frac{\frac{\sqrt{2}}{2} k_{\mathrm{rj}} \frac{A_{1}-A_{2}}{A_{\mathrm{j}}} C_{\mathrm{dj}} \sqrt{\frac{2}{\rho} p_{\mathrm{s}}}}{\sqrt{\left(k_{\mathrm{rj}}-\frac{A_{1}}{A_{\mathrm{j}}}\right)^{2}+\left(k_{\mathrm{rj}}-\frac{A_{2}}{A_{\mathrm{j}}}\right)^{2}+2 \frac{A_{1} \cdot A_{2}}{A_{\mathrm{j}}^{2}}}}
$$

where $C_{\mathrm{dj}}$ is the flow coefficient of jet nozzle, which chooses 0.91 .

Near $y=0$, linear flow characteristics can be written as

$$
q_{\mathrm{L}}=K_{\mathrm{q} 0} y=\frac{\partial q_{L}}{\partial y} y=k_{\mathrm{rj}} \pi R_{\mathrm{j}} C_{\mathrm{d}} \sqrt{\frac{2}{\rho} \frac{p_{s}}{1+\left(2 k_{\mathrm{rj}}-1\right)^{2}}} y
$$




\section{Simulation}

Based on Eqs. (19), (22) and Table 1, the linear pressure characteristics and flow characteristics curves can be plotted as Fig.4 and Fig.5.

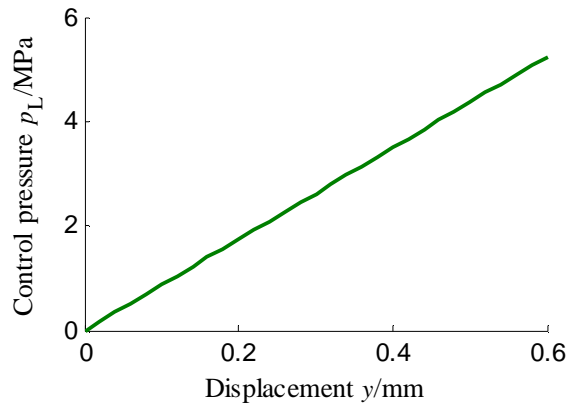

Fig. 4 Curves of pressure characteristics

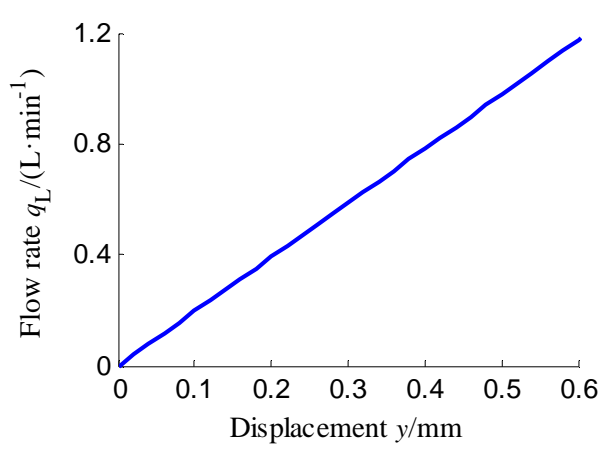

Fig. 5 Curves of flow characteristics

Table 1 Parameters' value of JTHA

\begin{tabular}{lcc}
\hline \multicolumn{1}{c}{ Parameters } & Symbol & value \\
\hline Supply pressure & $p_{s}$ & $0.6 \mathrm{MPa}$ \\
Nozzle diameter & $D_{\mathrm{j}}$ & $1.2 \mathrm{~mm}$ \\
Receiver hole diameter & $D_{\mathrm{r}}$ & $1.5 \mathrm{~mm}$ \\
\hline
\end{tabular}

\section{Conclusions}

The JTHA can be equivalent to full-bridge hydraulic resistor network madding up of four adjustable orifices. When the jet nozzle and receiving hole are concentric, the control pressure and flow of JTHA reaches the maximum value.

\section{Acknowledgments}

This work was supported by the National Natural Science Foundation of China (51605145) and the Science Foundation of Henan University of Science and Technology (2015QN013).

\section{References}

[1] Yuesong Li. Mathematical modelling and characteristics of the pilot valve applied to a jet-pipe/deflector-jet servovalve[J]. Sensors and Actuators A, 245(2016).p.150-159.

[2] Yuchuan Zhu and Yuesong Li. Development of a deflector-jet electrohydraulic servovalve using a giant magnetostrictive material [J]. Smart Materials and Structures, 23(2014),115001.

[3] K.S. Dhinesh, R.P. Andrew, R.B. Christopher, et al., A novel piezo-hydraulic aerospace servovalve. Part 1: design and modeling. Proceedings of the Institution of Mechanical Engineers, Part I, J. Syst. Control Eng., 227(2013),p.371-389.

[4] Hire Math S S, Singaperumal M. FE approach electro mechanical fluid interaction of jet pipe electrohydraulic Flow control servovalve[C]. 2003 ASME international mechanical engineering Congress, Washington D C, Novermber, 15-21.

[5] Somashekhar S H, Singaperumal M, and Kumar R K. Modeling the steady-state analysis of a jet-pipe electrohydraulic servovalve [J]. Journal of Systems and Control Engineering, 220(2006), p.109-129. 